\title{
In situ TEM Study of G-phase Precipitates under Heavy Ion Irradiation in CF8 Cast Austenitic Stainless Steel
}

\author{
Wei-Ying Chen ${ }^{1,2}$, Meimei Li ${ }^{1}$, Xuan Zhang ${ }^{1}$, Marquis A. Kirk ${ }^{1}$, Peter M. Baldo ${ }^{1}$, \\ Tiangan $\operatorname{Lian}^{3}$ \\ ${ }^{1}$ Argonne National Laboratory, Argonne IL, 60439, USA \\ ${ }^{2}$ University of Illinois at Urbana-Champaign, Urbana, IL, 61801, USA \\ ${ }^{3}$ Electric Power Research Institute, Palo Alto, CA 94304, USA
}

\begin{abstract}
Thermally-aged cast austenitic stainless steels (CASS) CF8 was irradiated with $1 \mathrm{MeV} \mathrm{Kr}$ ions at 300, 350 and $400^{\circ} \mathrm{C}$ to $1.88 \times 10^{19}$ ions $/ \mathrm{m}^{2}(\sim 3 \mathrm{dpa})$ at the IVEM-Tandem Facility at the Argonne National Laboratory. Before irradiation, the distribution of G-phase precipitates in the ferrite showed strong spatial variations, and both their size and density were affected by the ferrite-austenite phase boundary and presence of $\mathrm{M}_{23} \mathrm{C}_{6}$ carbides. Under $300^{\circ} \mathrm{C}$ irradiation, in situ TEM observation showed G-phase precipitates were relatively unchanged in the vicinity of the phase boundary $\mathrm{M}_{23} \mathrm{C}_{6}$ carbides, while the density of Gphase precipitates increased with increasing dose within the ferrite matrix. Coarsening of G-phase precipitates was observed in the vicinity of phase boundary $\mathrm{M}_{23} \mathrm{C}_{6}$ carbides at $350^{\circ} \mathrm{C}$ and $400^{\circ} \mathrm{C}$.
\end{abstract}

\section{Introduction}

Austenitic stainless steels are extensively used in nuclear reactors due to a combination of corrosion resistance, mechanical property and formability. Cast austenitic stainless steels and stainless steel welds have a duplex structure of austenite and ferrite (typically 5-30\% [1]). The presence of ferrite increases the strength and corrosion resistance. However, the instability of the ferrite phase at elevated temperatures below $500^{\circ} \mathrm{C}$ (known as $475^{\circ} \mathrm{C}$ embrittlement) causes spinodal decomposition, G-phase precipitation and $\mathrm{M}_{23} \mathrm{C}_{6}$ carbide precipitation, leading to degradations in mechanical properties [1][2][3][4]. Spinodal decomposition reaction is the instability of the ferrite phase that decomposes into Fe-rich $\alpha$ phase and $\mathrm{Cr}$ rich $\alpha^{\prime}$ phase. Spinodal decomposition has been recognized as the primary embrittlement mechanism [1][5]. G-phase precipitate has a cube-on-cube orientation relationship to the ferrite matrix. It has stoichiometric composition of $\mathrm{A}_{6} \mathrm{Ni}_{16} \mathrm{Si}_{7}$ where A could be $\mathrm{Cr}$ and $\mathrm{Mn}$, and Fe could substitute to the $\mathrm{Ni}$ site. 
The formation of G-phase precipitates is expected to harden and embrittle ferrite phase by acting as Orowan obstacles that impede the glide of dislocations. However, studies since 1990s reported inconsistent results, and the role of G-phase precipitates in the embrittlement of ferrite is still unclear. On one hand, atom probe tomography (APT) studies show that the hardening of ferrite is fully correlated to the $\mathrm{Cr}$ fluctuation of spinodal decomposition, and not affected by the precipitation of G-phase [6][7][8]. On the other hand, G-phase precipitates were shown to have considerable contribution to the hardening of ferrite, supported by recovery anneal experiments [9][10] and the observation of hardening rate changes [1]. Tensile and fracture property dependence on G-phase precipitates during aging is also ambiguous $[\mathbf{1}][4][\mathbf{1 1}][\mathbf{1 2}][\mathbf{1 3}][\mathbf{1 4}]$. The origin of the difficulty to distinguish spinodal decomposition and G-phase precipitation effects on ferrite embrittlement is primarily due to the significant overlap of the two phase transformations. In addition, it was proposed that G-phase precipitation depletes $\mathrm{Ni}$ in ferrite matrix and thereby hinders the spinodal decomposition [5]. Spinodal decomposition was suggested to accelerate the Gphase precipitation by producing $\mathrm{Ni}$ and $\mathrm{Si}$ diffusion flux across $\alpha / \alpha$ ' interfaces [7]. Mutual influences between spinodal decomposition and G-phase precipitation have further complicated the understanding of G-phase precipitation effect on ferrite embrittlement.

In addition to thermal aging, degradation due to irradiation is of concern since certain stainless steel welds near the reactor core might experience fast neutron fluence as high as $10^{26} \mathrm{n} / \mathrm{m}^{2}$ [15]. The combination of thermal aging and irradiation could accelerate deterioration of the weld integrity and CASS components. In spite of the extensive studies on aging effect, the irradiation effect and its synergistic effect with aging is less understood. Earlier irradiation studies on ferritic steels show that neutron irradiation would accelerate G-phase precipitation and spinodal decomposition [6][16][17]. Recent fracture toughness study in cast austenitic stainless steel (CASS) shows that the loss of toughness caused by neutron irradiation was less significant in the thermally-aged than in the as-received (unaged) specimens [18]. Aging and neutron irradiation study in weld overlay cladding shows a higher ductile-to-brittle transition temperature (DBTT) in irradiated samples compared to aged samples [19].

To predict long-term mechanical properties of austenitic stainless steel welds, and duplex stainless steel in general, it is important to understand the precipitation and the stability of G-phase under irradiation and 
aging. In this study, thermally-aged CASS CF8 was examined to study the combined effects of thermal aging and irradiation damage. Irradiation experiments were performed using $1 \mathrm{MeV} \mathrm{Kr}$ ions at $300-400^{\circ} \mathrm{C}$ with in situ TEM observations. Ion irradiation is an accelerated tool to understand the neutron irradiation effect. The evolution G-phase precipitates as a function of irradiation doses was investigated. The experiments provide information about the microstructural dependence on the irradiation and thermal-aging conditions.

\section{Experimental Procedure}

\subsection{Materials}

Thermally-aged CF8 steels were examined in this study. The nominal chemical composition of CF8 is given in Table 1 [18]. Thermal aging treatment was conducted at $400^{\circ} \mathrm{C}$ for 10,000 hours. CF8 steels have a duplex structure of ferrite and austenite as shown in Fig. 1. Metallographic measurements showed that the ferrite content is about $15 \%$. The morphology of ferrite in the CF8 was similar before and after the thermal aging treatment.

\subsection{Irradiation Experiments}

Disc specimens of $3 \mathrm{~mm}$ in diameter were punched from a thin sheet and subsequently electropolished to perforation using a Tenupol twin-jet polishing unit with an electrolyte of 5\% perchloric acid plus 95\% methanol at $-35^{\circ} \mathrm{C}$. The electron-transparent thin foil specimens were irradiated in situ with $1 \mathrm{MeV} \mathrm{Kr}$ ions at 300,350 and $400^{\circ} \mathrm{C}$ at the IVEM-Tandem Facility at the Argonne National Laboratory. The specimens were irradiated with an incident angle around $15^{\circ}$ from the specimen normal, while the microstructure was observed in situ with $200 \mathrm{keV}$ electrons. A Faraday cup in the microscope at $2 \mathrm{~cm}$ from the specimen was used to measure the ion dosimetry. The temperature was controlled by heating the TEM sample holder. The specimen was irradiated to an ion fluence of $6.3 \times 10^{18}$ ions $/ \mathrm{m}^{2}(\sim 1 \mathrm{dpa})$ at an ion flux was $1.6 \times 10^{15}$ ions $/ \mathrm{m}^{2} / \mathrm{sec}$, and to a high fluence at an increased flux of $6.2 \times 10^{15}$ ions $/ \mathrm{m}^{2} / \mathrm{sec}$. The final fluence was $1.9 \times 10^{19} \mathrm{ions} / \mathrm{m}^{2}(\sim 3 \mathrm{dpa})$.

The damage profile of $1 \mathrm{MeV} \mathrm{Kr}$ ion irradiations in the CF8 stainless steels was calculated with SRIM2012 [20] using the quick damage mode with average displacement energies of 40 and $45 \mathrm{eV}$ for $\mathrm{Fe}$ and $\mathrm{Cr}$ 
atoms, respectively [21]. Fig. 2 shows the depth profile of the atomic displacement and the distribution of implanted $\mathrm{Kr}$ ions in the ferrite phase to a depth of $100 \mathrm{~nm}$. The calculations indicated that in average only about 0.4 at. $\%$ of the irradiated $\mathrm{Kr}$ ions were retained in the foil of $100 \mathrm{~nm}$ thickness. In addition, the damage (Frenkel pair production) was reasonably uniform across the foil thickness.

The following equation was used to calculate the dpa values:

$$
d p a=\frac{\Phi \times 10^{4} \times D}{N}
$$

where $\Phi$ is the fluence in ions $/ \mathrm{m}^{2}, D$ is the damage rate in vacancies/ion/ $\AA$ and $N$ is the atomic number density in atoms $/ \mathrm{cm}^{3}$. An average damage rate of 1.3 vacancies/ion/Å was estimated according to the SRIM calculation in Fig. 2. N was estimated using a lattice parameter of $2.87 \AA$ [22].

\subsection{TEM}

The G-phase precipitates in ferrite were viewed in TEM with kinematic bright-field and centered dark-field using G-phase diffraction spots. Because of the small G-phase volume fraction, the reflection of G-phase could not be identified readily at the major zone orientation of ferrite. However, strong G-phase reflections could be identified when ferrite was tilted close to certain minor zone of ferrite [23], and could be used to produce the dark-field images of G-phase precipitates. The foil thickness was measured by the thickness fringes in dark-field with a diffraction condition of $g=(110)(\mathrm{g}, 5 \mathrm{~g})$ of the ferrite matrix.

The uncertainty of density measurements was estimated by applying a $50 \%$ confidence factor to the defects with relatively weak contrast. The size of the precipitates was measured manually with imaging software ImageJ. An uncertainty of $1 \mathrm{~nm}$ was estimated for the uncertainty of the size measurement.

\section{Results}

\subsection{Microstructure prior to irradiation}

In the thermally-aged $\mathrm{CF} 8$ specimen, $\mathrm{M}_{23} \mathrm{C}_{6}$ carbides, G-phase precipitates and $\alpha^{\prime}$ phase were observed. $\mathrm{M}_{23} \mathrm{C}_{6}$ carbides were located at the phase boundary. The precipitation of G-phase and $\alpha^{\prime}$ phase in ferrite in aged CF8 specimens was confirmed by the APT analysis in a companion study [24]. The G-phase 
precipitates with a mean size of $3 \mathrm{~nm}$ existed in the ferrite matrix, as shown in Fig. 3. The precipitates decorating dislocations were larger with a mean size of about $6 \mathrm{~nm}$. The density and size of G-phase precipitates in ferrite were found to be locally affected by the $\mathrm{M}_{23} \mathrm{E}_{6}$ carbide and the phase boundary.

Fig. 4 shows the ferrite-austenite phase boundary in an unirradiated aged CF8 specimen. $\mathrm{M}_{23} \mathrm{C}_{6}$ carbides of a width of 50-100 nm were found partially covering the phase boundary. Apparent distinction of the size and density distribution of G-phase precipitates was observed between the case with and without $\mathrm{M}_{23} \mathrm{C}_{6}$ carbides. Since spinodal decomposition caused a mottled contrast that degraded the imaging quality of Gphase precipitates, especially for the smaller ones, dark-field imaging using the G-phase diffraction spots was performed for detailed investigation described as follows.

Fig. 5 shows the distribution of G-phase precipitates in ferrite in the vicinity of $\mathrm{M}_{23} \mathrm{C}_{6}$ carbides located at the phase boundary. A dashed line is placed to indicate the $\mathrm{M}_{23} \mathrm{C}_{6}$-decorated phase boundary due to the weak contrast for the ferrite-austenite phase boundary and $\mathrm{M}_{23} \mathrm{C}_{6}$ carbides in the dark-field using the Gphase reflection. The G-phase precipitates close to the carbides were as large as 6-7 $\mathrm{nm}$, and were faceted on $\{100\}$ planes. The size decreased with increasing distance to the phase boundary until reaching a saturation size of $3 \mathrm{~nm}$. The density increased with increasing distance to the phase boundary, and a local maximum was observed at a distance of $350 \mathrm{~nm}$, as shown in Fig. 5 where the size, density and the corresponding volume fraction of G-phase precipitates in ferrite is given as a function of the distance to the phase boundary. The uncertainty for the density measurements was about the same size as the data marker in Fig. 6 (a). A representative uncertainty of $1 \mathrm{~nm}$ for size measurement was shown in in Fig. 6 (b). The uncertainty bar for the volume fraction was obtained as a result of the uncertainty propagation of size and density measurements.

For the phase boundary without the presence of $\mathrm{M}_{23} \mathrm{C}_{6}$ carbide, the density of G-phase precipitates increased monotonically with increasing distance to phase boundary while the size remained constant as 3 $\mathrm{nm}$. A denuded zone of about $50 \mathrm{~nm}$ wide was observed at phase boundary, independent of phase-boundary carbides. The TEM measurements of G-phase precipitate distributions in ferrite of aged CF3M steels by 
Hamaoka et al.[27] are included in Fig. 6 for comparison. CF3M steels have similar duplex structure but slightly different chemical composition from CF8 steels. The lower carbon content in CF3M results in an absence of carbides at the ferrite-austenite phase boundary [23].

\subsection{G-phase Stability under Irradiation}

The G-phase precipitates in ferrite before and after $1 \mathrm{MeV} \mathrm{Kr}$ ion irradiation to $6.3 \times 10^{18}$ ions $/ \mathrm{m}^{2}(\sim 1 \mathrm{dpa})$ at $300^{\circ} \mathrm{C}$ in aged $\mathrm{CF} 8$ specimens are shown in Fig. 7 and Fig. 8 for the areas distant to (> $\left.1 \mu \mathrm{m}\right)$ or close to $(\sim 100 \mathrm{~nm})$ the phase boundary decorated with the $\mathrm{M}_{23} \mathrm{C}_{6}$ carbide, respectively. Fig. 9 shows the corresponding quantitative measurements, including the size, density and volume fraction of G-phase precipitates. In situ real-time TEM observations revealed coarsening, dissolution and formation of individual G-phase precipitates under irradiation. In both areas, G-phase precipitates were produced or dissolved under irradiation while some precipitates remained intact. However, the overall effects of irradiation on the G-phase microstructures were found distinct between the two areas. In the area distant from the phase boundary (Fig. 7), both the density and size increased with irradiation dose, leading to an increase in volume fraction. In contrast, in the vicinity of the phase boundary with $\mathrm{M}_{23} \mathrm{C}_{6}$ carbides (Fig. 8), much more G-phase precipitates were dissolved than being produced. The average precipitates size also decreased. As a result, the volume fraction of G-phase precipitates in this area decreased. The size difference in G-phase precipitates between the two areas seems to be reduced after irradiation.

\subsection{G-phase Coarsening under Irradiation}

Coarsening behavior of G-phase precipiates under irradiation was examined in the vicinity of the ferriteaustenite phase boundary with $\mathrm{M}_{23} \mathrm{C}_{6}$ carbides where the size of G-phase precipitates is relatively large and the precipitates are readily identifiable. Fig. 10 and Fig. 11 show the evolution of G-phase precipitates in ferrite in the aged CF8 irradiated at 300 and $400^{\circ} \mathrm{C}$, respectively. Images in each figure were taken of the constant specimen area to monitor the size change of individual G-phase precipitates as the irradiation dose increased. The imaging condition was BF with $\mathrm{g}=110$ close $(001)$ zone. Fig. 12 shows the change in the mean size of G-phase precipitates as a function of dose at 300,350 and $400^{\circ} \mathrm{C}$. The measurements were conducted by sampling precipitates within a similar distance $(150-200 \mathrm{~nm})$ to the phase boundary for all 
three temperatures. The mean size of the G-phase precipitates increased continuously with irradiation doses at $350^{\circ} \mathrm{C}$ and $400^{\circ} \mathrm{C}$, but was relatively unchanged at $300^{\circ} \mathrm{C}$.

\section{Discussion}

As described in section 3.1, a fine dispersion of G-phase precipitates was observed in the ferrite of the aged CF8 specimen. Dislocations promote the nucleation and growth of precipitation [23], resulting in larger Gphase precipitates at dislocations as shown in Fig. 3. The distribution of G-phase precipitates was also affected by the environment of austenite-ferrite phase boundary: for the phase boundary without $\mathrm{M}_{23} \mathrm{C}_{6}$, the precipitate volume density decreased with decreasing distance to the phase boundary while the precipitate size was unchanged; on the other hand, for the phase boundary with $\mathrm{M}_{23} \mathrm{C}_{6}$, enhanced G-phase growth in the vicinity of the $\mathrm{M}_{23} \mathrm{C}_{6}$ has been observed. The inhomogeneous distribution of G-phase precipitates was also observed in the thermally-aged CF3M by Hamoka et al., and the low density of G-phase precipitates in the vicinity of the phase boundary was suggested to be associated with the depletion of $\mathrm{Mo}, \mathrm{Si}$ and $\mathrm{Ni}$ elements [27]. Due to a higher carbon concentration in $\mathrm{CF} 8$ than in $\mathrm{CF} 3 \mathrm{M}, \mathrm{M}_{23} \mathrm{C}_{6}$ carbides were often observed at the phase boundary, and the distribution of G-phase precipitates is strongly dependent on the presence of $\mathrm{M}_{23} \mathrm{C}_{6}$ carbides, as shown in Fig. 5. The large sizes and higher volume fraction of the G-phase precipitates observed near $\mathrm{M}_{23} \mathrm{C}_{6}$ carbides in CF8 may be understood by an enrichment of elements such as $\mathrm{Ni}, \mathrm{Si}$ and $\mathrm{Mn}$ near its vicinity, which may be ejected from the precipitation of $\mathrm{M}_{23} \mathrm{C}_{6}$ carbide at the phase boundary [28][29]. In addition, the two curves (with and without $\mathrm{M}_{23} \mathrm{C}_{6}$ carbides in Fig. 5) merge at about 1 $\mu \mathrm{m}$, indicating the local environment difference diminishes there. To support the proposed mechanisms above, analytical TEM, APT studies and computer modeling are required.

The stability of precipitates in alloys subjected to intense irradiation has received long-term attention [30][31]. Various models [32][33][34][35][36], focusing on the effect of competition between ballistic mixing and thermal diffusion, have been proposed to rationalize the experimental observation of precipitate re-distribution. The inhomogeneous distribution of G-phase precipitates in the ferrite of the thermally-aged CF8 complicates the analysis. TEM with in situ ion irradiation is a powerful tool in understanding the evolution of heterogeneous microstructure under irradiation by monitoring microstructure in different specimen areas. In our in situ irradiation experiment, we observed that larger G-phase precipitates near 
phase boundary $\mathrm{M}_{23} \mathrm{C}_{6}$ (average size $\sim 5 \mathrm{~nm}$ ) relatively unchanged under irradiation at $300^{\circ} \mathrm{C}$, while in the region away from phase boundary $\mathrm{M}_{23} \mathrm{C}_{6}$ some precipitates dissolved, but more were formed, leading to an increase in the precipitate density under irradiation. The average size of TEM resolvable precipitates was 3.1 and $3.7 \mathrm{~nm}$ before and after irradiation. When the irradiation temperature increased to 350 and $400^{\circ} \mathrm{C}$, the mean size of G-phase precipitates measured by TEM increased with increasing dose in the vicinity of $\mathrm{M}_{23} \mathrm{C}_{6}$ carbides at the ferrite-austenite phase boundary, while G-phase precipitates measured by atom probe tomography (APT) [24] showed a size reduction (i.e. inverse coarsening) in the ferrite matrix away from the boundary. It should be noted that APT can resvolve smaller sizes of precipitates than TEM. Clearly the G-phase precipitates responded differently to irradiation depending on their distribution. The different behavior of G-phase may be understood by considering competing processes under irradiation, i.e. irradiation-enhanced diffusion, recoil dissolution, and radiation-induced segregation at the phase boundary. Both irradiation ballistic mixing and diffusion considerably affected the state of G-phase precipitation under irradiation. The relative importance between the two mechanisms depends on irradiation temperatures. As irradiation temperature increases, diffusion is enhanced while ballistic mixing becomes comparably unimportant, resulting in the proceeding of precipitate coarsening. Analytical measurement of composition profiles in the phase boundary region before and after irradiation is needed to fully understand the different evolution kinetics of G-phase. It should also be mentioned that the time needed to achieve steady state under heavy ion irradiation is much longer than typical experimental time (days compared to hours), as have been shown with the Frost-Russell model on particle stability with recoil resolution [33][34]. Therefore, what we have observed here could be the initial stage of the structural evolution.

Finally, the surface effect is a unique characteristic of in situ ion irradiation experiments in TEM. The TEM foil thickness used in in situ irradiation experiments was typically $\sim 100 \mathrm{~nm}$. The foil surface is effective defect sink where point defects and small defect clusters can migrate to and annihilate [37]. The flow of point defects and small defect clusters may affect the stability and the spatial homogeneity of G-phase precipitates under irradiation. The surface effect, however, was not significant in this study because the mobility of point defects and defect clusters was greatly suppressed in alloys compared to pure metal [38]. The real time observation using a Gatan 622 video camera showed no detectable motion of defect clusters 
in this study. In addition, the surface effect to point defects was evaluated by investigating the correlation between foil thickness and the areal density of G-phase precipitates after irradiation [39]. No evident surface effect on the G-phase precipitates was observed.

\section{Conclusion}

Thermally-aged CF8 cast stainless steels were irradiated with $1 \mathrm{MeV} \mathrm{Kr}$ ions at 300,350 and $400^{\circ} \mathrm{C}$ to $1.9 \times 10^{19}$ ions $/ \mathrm{m}^{2}(\sim 3 \mathrm{dpa})$ at Argonne IVEM-Tandem Facility. Pre-irradiation TEM characterization revealed spatial variation in number density and size of G-phase precipitates in ferrite in CF8 thermally aged at $400^{\circ} \mathrm{C}$ for $10,000 \mathrm{~h}$. The mean size of G-phase precipitates in the ferrite matrix was about $3 \mathrm{~nm}$, while larger G-phase precipitates were observed in the vicinity of phase boundary decorated with $\mathrm{M}_{23} \mathrm{C}_{6}$ carbides.

Evolution of G-phase precipitates was followed by TEM during in situ ion irradiation near the phase boundary and within the ferrite matrix. Irradiation at $300^{\circ} \mathrm{C}$ caused dissolution, re-precipitation, coarsening and shrinking of G-phase precipitates. In the vicinity of the phase boundary with $\mathrm{M}_{23} \mathrm{C}_{6}$ carbides, the total density and mean size of G-phase precipitates were relatively unchanged after irradiation, while the number density of G-phase increased after irradiation in the area away from the boundary. Coarsening behavior of G-phase precipitates near the phase boundary was studied by monitoring the size change of individual Gphase precipitates in the constant specimen area. The mean size of the precipitates increased after irradiation at $350^{\circ} \mathrm{C}$ and $400^{\circ} \mathrm{C}$, but not at $300^{\circ} \mathrm{C}$.

\section{Acknowledgments}

This work was supported by Electric Power Research Institute. The ion irradiation was accomplished at Argonne National Laboratory at the IVEM-Tandem Facility, a user facility funded by the US Department of Energy Office of Nuclear Energy, operated under Contract No. DE-AC02-06CH11357 by UChicago Argonne, LLC..Yiren Chen at ANL is thanked for providing the materials, helpful discussion, and conducting the paper review. 


\section{Reference}

[1] J.M Vitek, S.A. David, D.J. Alexander, J.R. Keiser, R.K. Nanstad, Acta Metall. Mater. 39 (1991), p. 503

[2] K.B. Alexander, M.K. Miller, D.J. Alexander and R.K. Nanstad, Master. Sci. Tech. 6 (1990) 314

[3] S.A. David, J.M. Vitek, J.R. Keiser and W.C. Oliver, Weld. J. 66 (1987) 235s

[4] G.E. Hale, J.R. Gordon and B. Hemsworth, in Environmental Degradation of Materials in Nuclear Power Systems - Water Reactors (edited by G. J. Theus and J.R. Weeks), pp. 723-730. T.M.S. -A.I.M.E., Warrendale, $\mathrm{Pa}(1988)$

[5] H.M. Chung, Int. J. Pres. Ves. \& Piping 50 (1992), p. 179

[6] T. Takeuchi, Y. Kakubo, Y. Matsukawa, Y. Nozawa, T. Toyama, Y. Nagai, Y. Nishiyama, J. Katsuyama, Y. Yamaguchi, K. Onizawa, Journal of Nuclear Materials 449 (2014), p. 273

[7] F. Danoix, P. Auger, D. Blavette, Surface Science 266 (1992), p. 364

[8] C. Pareige, S. Novy, S. Saillet, P. Pareige, Journal of Nuclear Materials 411 (2011), p. 90

[9] T. Yamada, S. Okano, H. Kuwano, Journal of Nuclear Materials 350 (2006), p. 47

[10] F. Danoix, P. Bas, J.P. Massoud, M. Guttmann, P. Auger, Appl. Surf. Sci. 67 (1993), p. 348

[11] J.J. Shiao, C.H. Tsai, J.J. Kai, J.H. Huang, Journal of Nuclear Materials 217 (1994), p.269

[12] S. Kawaguchi, N. Sakamoto, G. Takano, F. Matsuda, Y. Kikuchi, L. Mráz, Nuclear Engineering and Design 174 (1997), p. 273

[13] Chung and Chopra, Proc. 3rd intl. Symp. on Environmental Degradation and Materials in Nuclear Power Systems - Water Reactors, ed. G. J. Theus, \& J.R. Weeks. The Metallurgical Society, Warrendale, PA (1988) p. 359

[14] D.J. Alexander et al., Recent Trends in Welding Science and Technology (edited by S.A. David and J.M. Vitek), p. 217

[15] K. Fujii and K. Fukuya, Journal of Nuclear Materials 440 (2013), p.612.

[16] M.K. Miller, R.E. Stoller and K.F. Russell, Journal of Nuclear Materials 230 (1996), p.219.

[17] V. Kuksenko, C. Pareige, C. Genevois, F. Cuvilly, M. Roussel and P. Pareige, Journal of Nuclear Materials 415 (2011), p. 61.

[18] Y. Chen et al., 16th Inter. Conf. on Environmental Degradation of Materials in Nuclear Power Systems

[19] Y. Nishiyama et al. JAERI-Research 2000-47 (2000)

[20] J.F. Ziegler, J.P. Biersack, U. Littmark, New York, 1985.

[21] M. Tikhonchev, V. Svetukhin, A. Kadochkin and E. Gaganidze, Journal of Nuclear Materials 395 (2009), p. 50.

[22] P. Olsson, I.A. Abrikosov, L. Vitos, J. Wallenius, Journal of Nuclear Materials 321 (2003), p.84.

[23] H.M. Chung, and T.R. Leax, Materials Science and Technology 6 (1990), p.292.

[24] M. Li, M.K. Miller, W-Y. Chen, Journal of Nuclear Materials (2015) in press.

[25] H.M. Chung and O.K. Chopra. NUREG/CR-4744-Vol. 3-No. 2, Nuclear Regulatory Commission, Washington, DC.

[26] M.K. Miller and J. Bentley, Materials Science and Technology 6 (1990), p.285.

[27] T. Hamaoka, A. Nomoto, K. Dohi and N. Soneda, Philosophical Magazine 92 (2012), p. 2716.

[28] S.S. Babu, S.A. David, J.M. Vitek and M.K. Miller, Metallurgical and Materials Transactions A 27 (1996), p. 763.

[29] Y. Miao. Private communication

[30] Wilkes P, JNM 83 (1979), p. 166.

[31] Bellon P, in Materials Science with Ion Beams, Topics in Applied Physics 116 (2010), p. 29

[32] R.S. Nelson, J.A. Hudson, D.J. Mazey, J. Nucl. Mater. 44 (1972), p. 318.

[33] H.J. Frost, K.C. Russell, J. Nucl. Mater. 103-104 (1981) p. 1427

[34] H.J. Frost, K.C. Russell, Acta Metall. 30 (1982), p. 953

[35] R.A. Enrique, P. Bellon, Phys. Rev. Lett. 84 (2000), p. 2885

[36] R.A. Enrique, P. Bellon, Phys. Rev. B 63 (2001), p. 134111

[37] G.S. Was, Fundamentals of radiation materials science: metals and alloys, Springer, New York, 2007.

[38] Z. Yao, M. Hernández-Mayoral, M.L. Jenkins, M.A. Kirk, Philosophical Magazine 88 (2008), p. 2851

[39] M. Li, M.A. Kirk, P.M. Baldo, D. Xu, B.D. Wirth, Philosophical Magazine 92 (2012), p. 2048. 


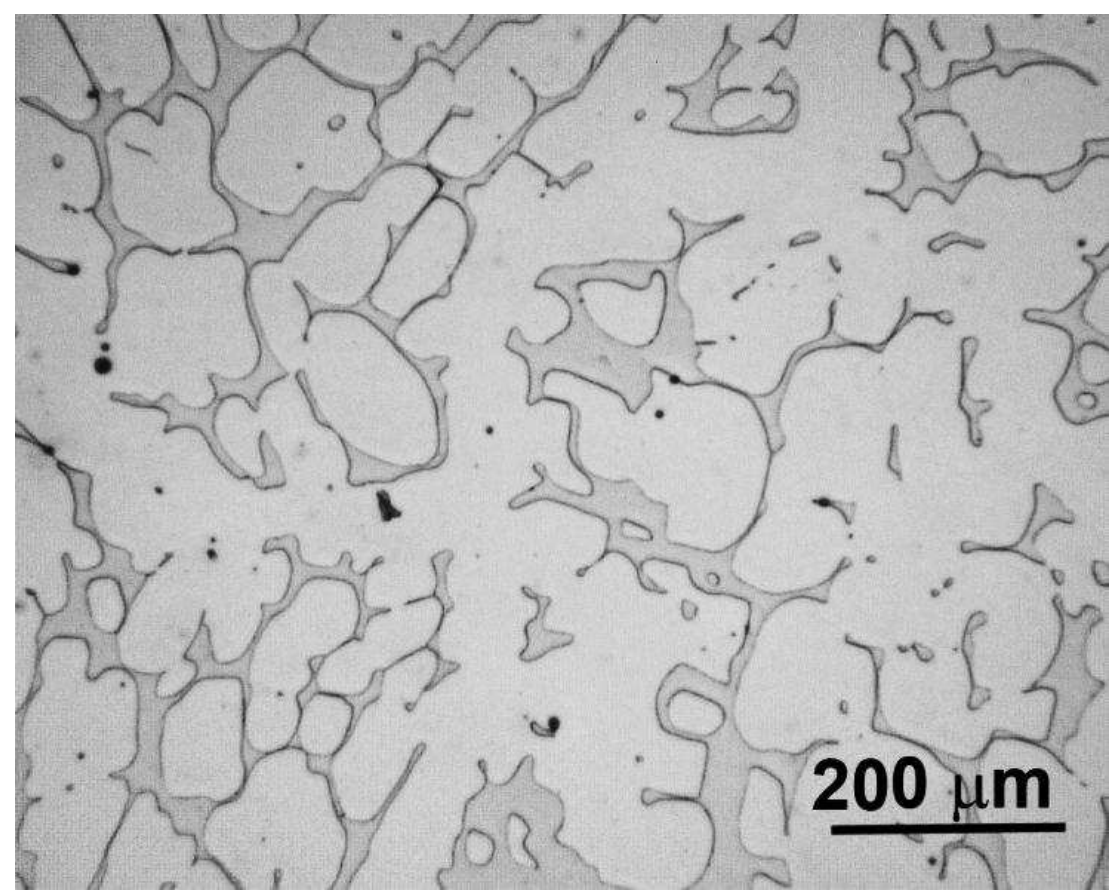

Fig. 1 The optical image of the aged CF8 steel specimen. The dark area is ferrite and the bright area are is austenite. 


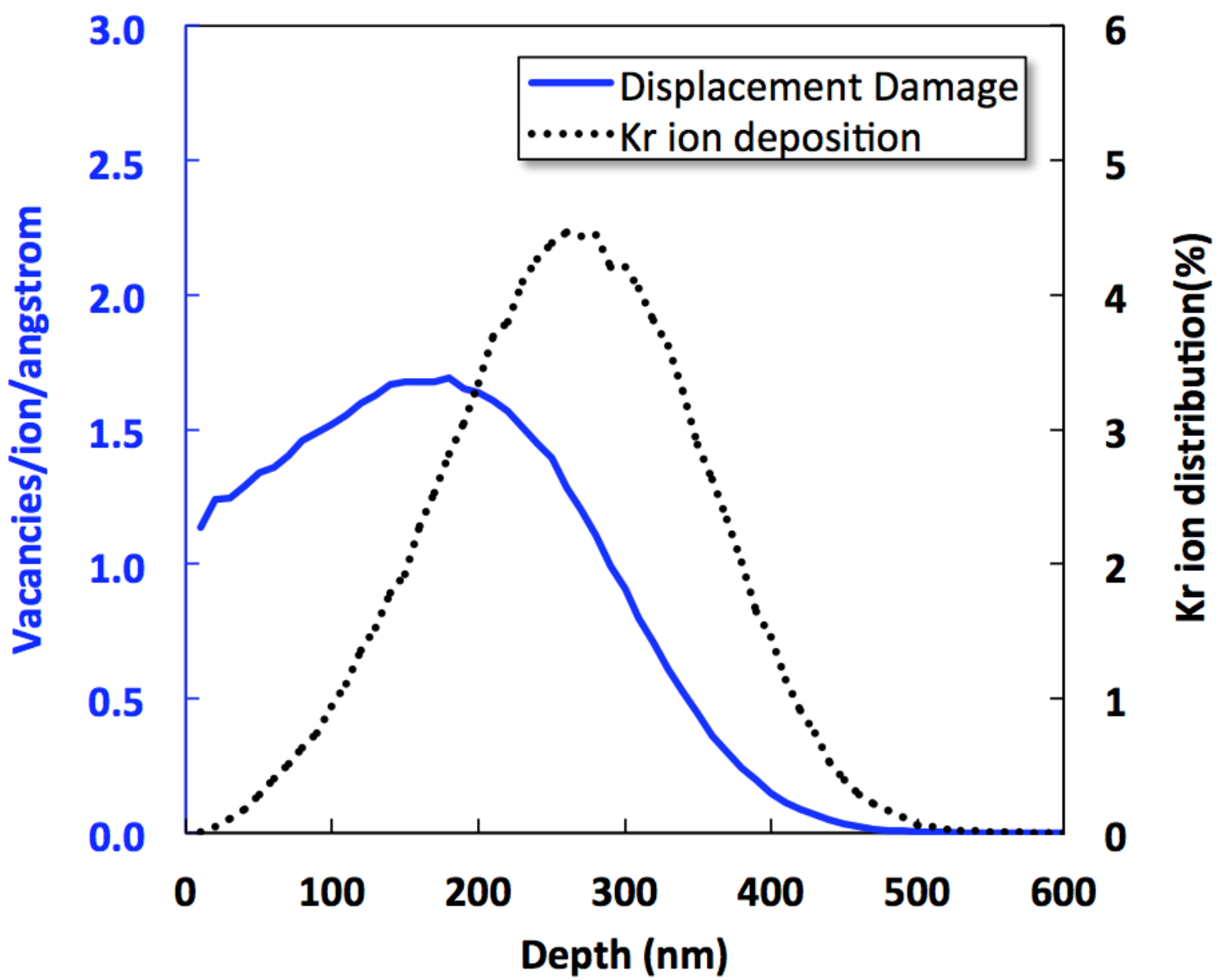

Fig. 2. Quick damage calculation with SRIM-2012 showing the depth profile of the irradiation damage and the $\mathrm{Kr}$ ion deposition in $\mathrm{CF} 8$ stainless steel irradiated with $1 \mathrm{MeV} \mathrm{Kr}$ ions. 


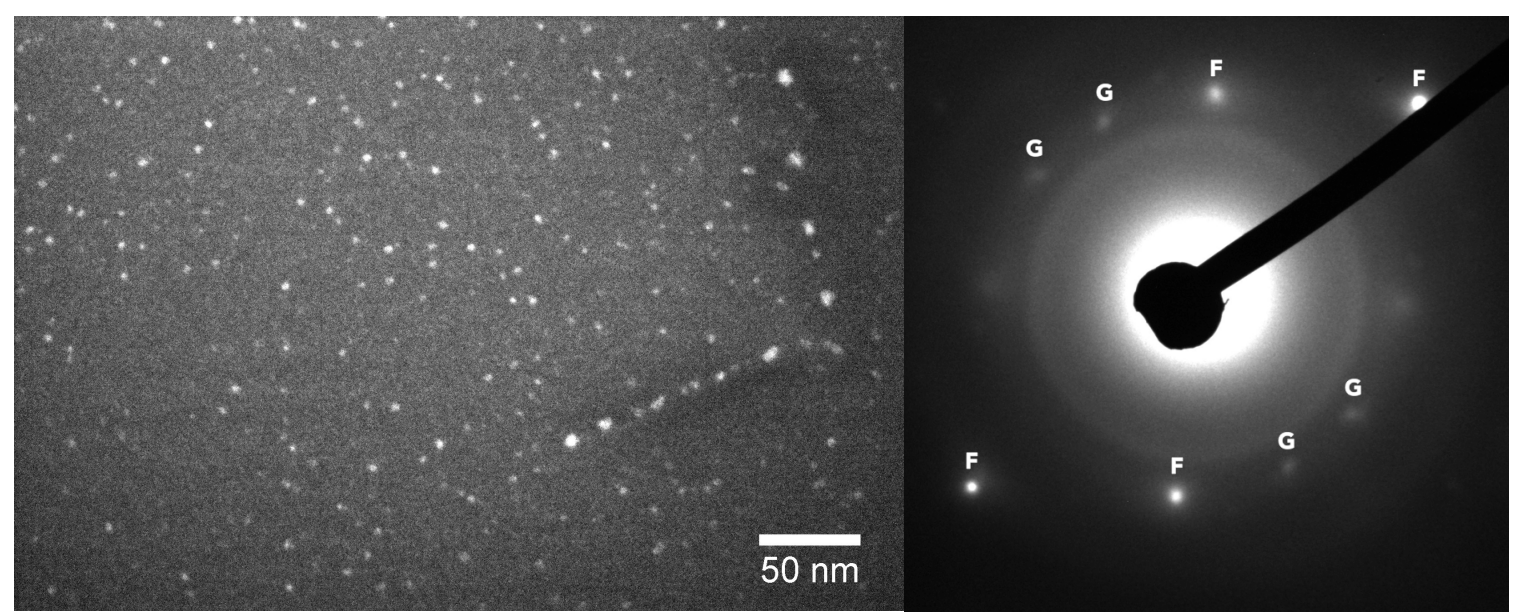

Fig. 3. (Left) The dark-field image of the ferrite phase in unirradiated aged CF8 specimen from an area distant to phase boundary. The image was taken with G-phase reflection. The incident electron beam was close to the [001] direction of the ferrite phase. The white contrast corresponds to G-phase precipitates. (Right) The corresponding diffraction pattern where label $\mathrm{F}$ and $\mathrm{G}$ indicate the diffraction spots of ferrite and G-phase precipitates, respectively.
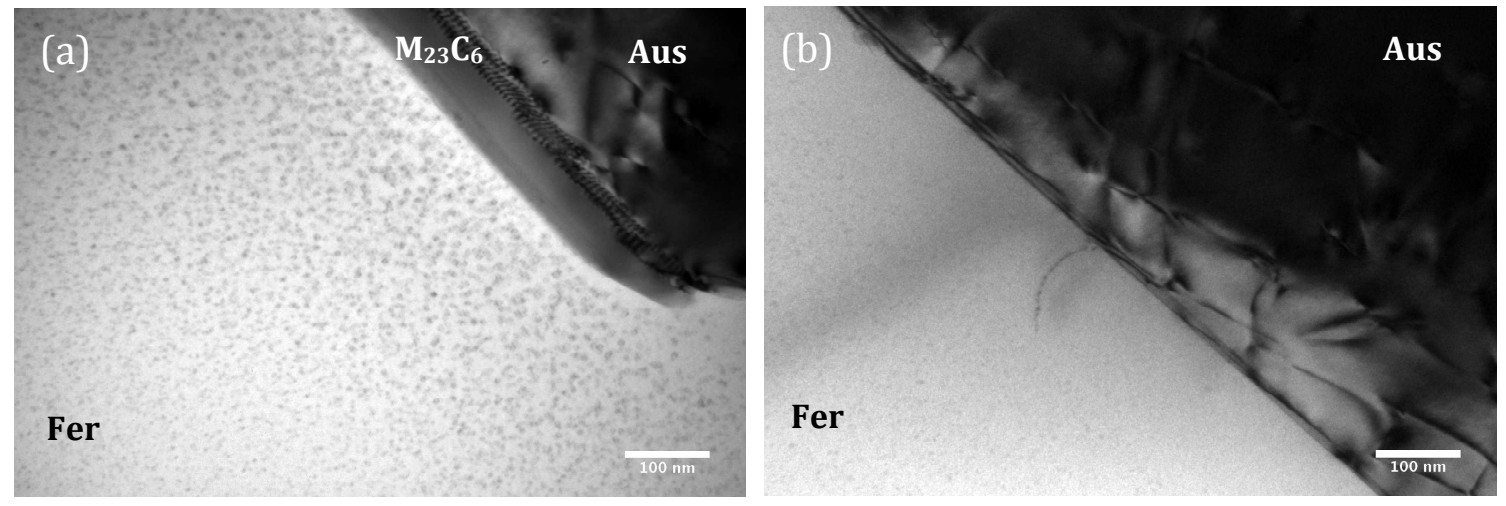

Fig. 4. Bright-field TEM images of phase boundaries (a) with and (b) without $\mathrm{M}_{23} \mathrm{C}_{6}$ carbides in an unirradiated aged CF8 specimen. Labels Aus and Fer correspond to austenite and ferrite phases, respectively. The gray particles in ferrite phase correspond to G-phase precipitates. The two subfigures were taken from nearby areas with the same diffraction condition of $\mathbf{g}=110$ close to (001) zone of ferrite. 


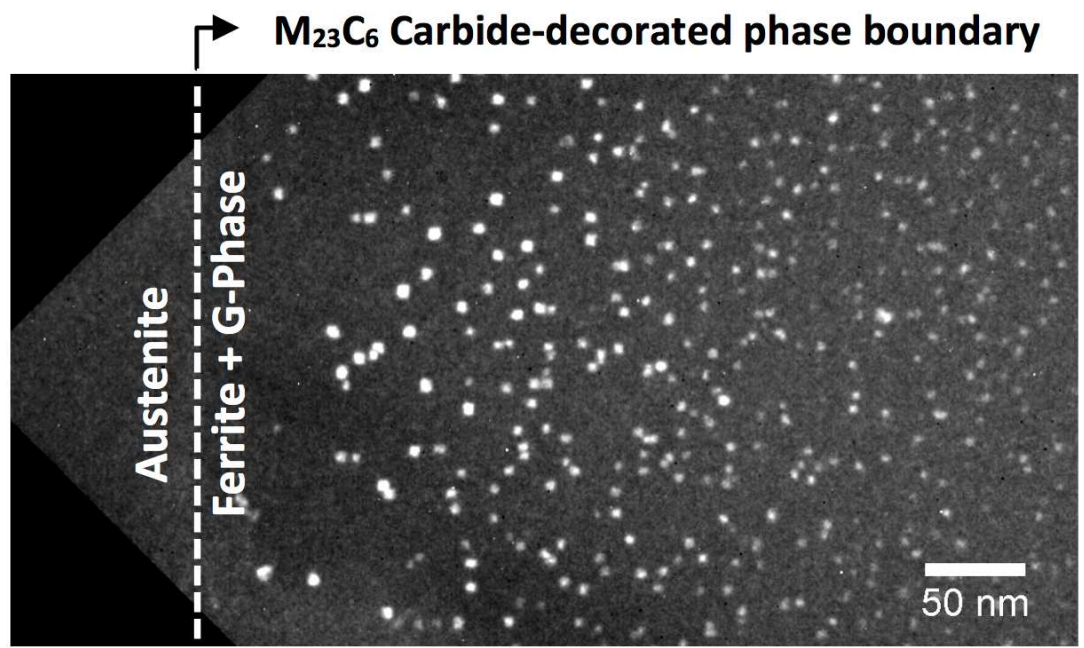

Fig. 5. The dark-field image of the ferrite phase in an unirradiated aged CF8 specimen from an area in the vicinity of $\mathrm{M}_{23} \mathrm{C}_{6}$ carbide at the phase boundary. The image was taken with the use of G-phase reflection where the incident electron beam was close to the [001] direction of the ferrite phase. The white contrast corresponds to G-phase precipitates. 
(a) Density of G-phase Precipitates

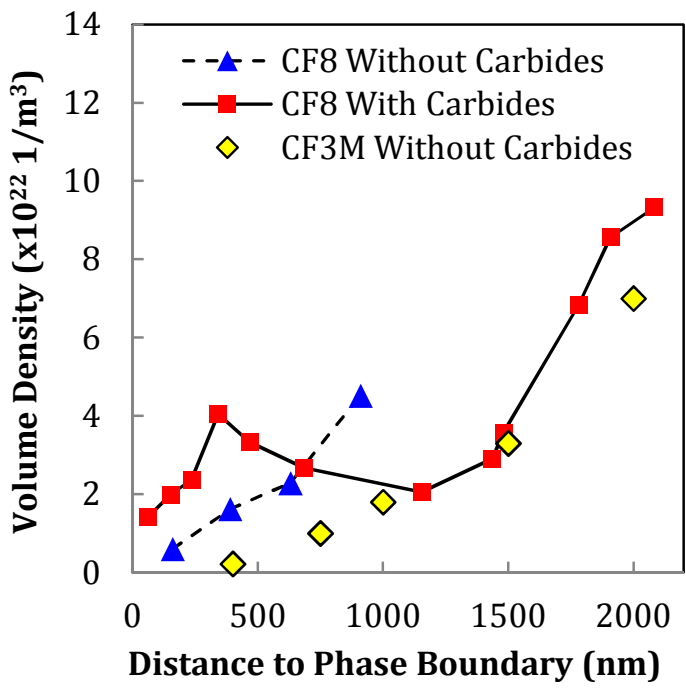

(b) Size of G-phase precipitates

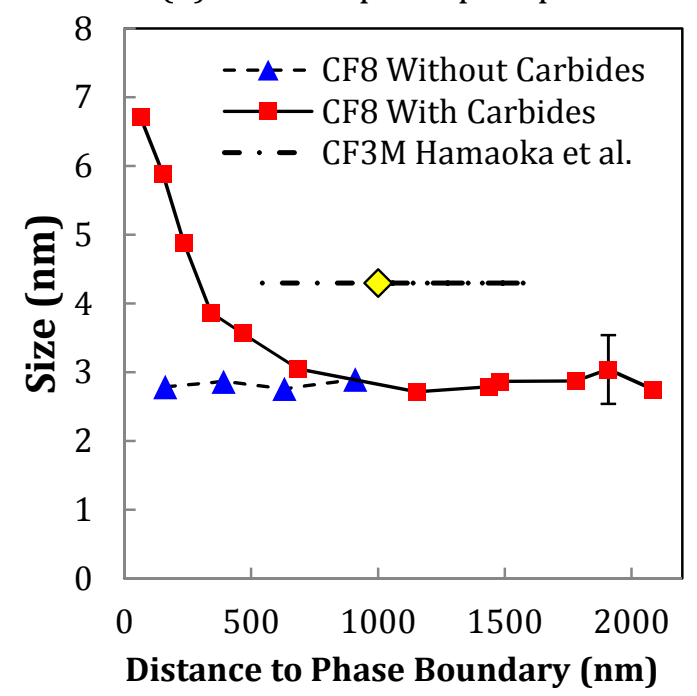

(c) Volume fraction of G-phase precipitates

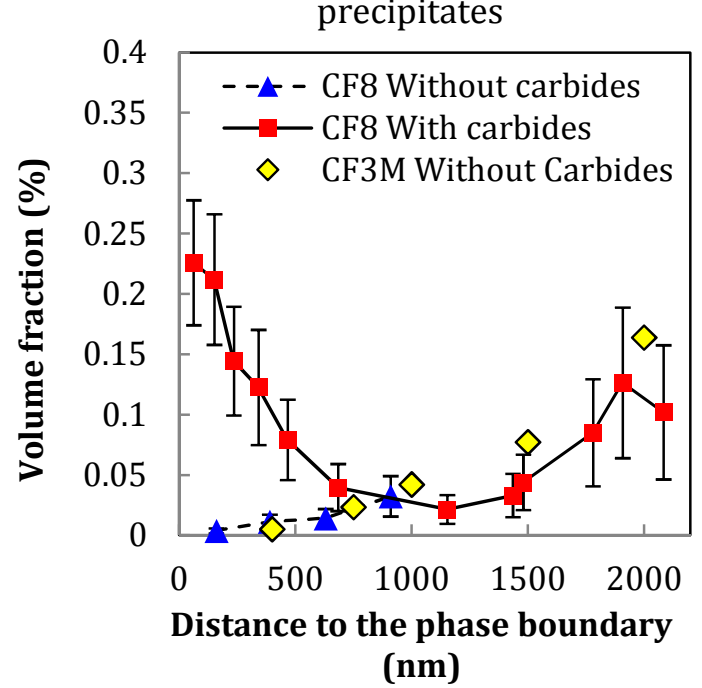

Fig. 6. (a) The density, (b) size and (c) volume fraction of G-phase precipitate in aged CF8 (this work) and CF3M (Hamaoka et al. [27]) specimens as a function the distance from the phase boundary and the carbides at the phase boundary. In [27], only one precipitate size in aged CF3M was reported for areas within $1.6 \mu \mathrm{m}$ from the phase boundary. 


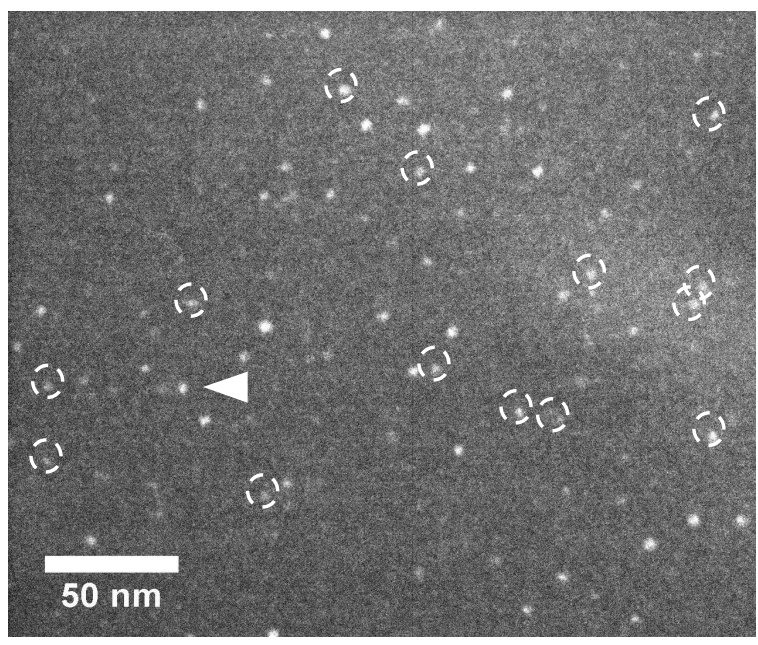

Before Irradiation

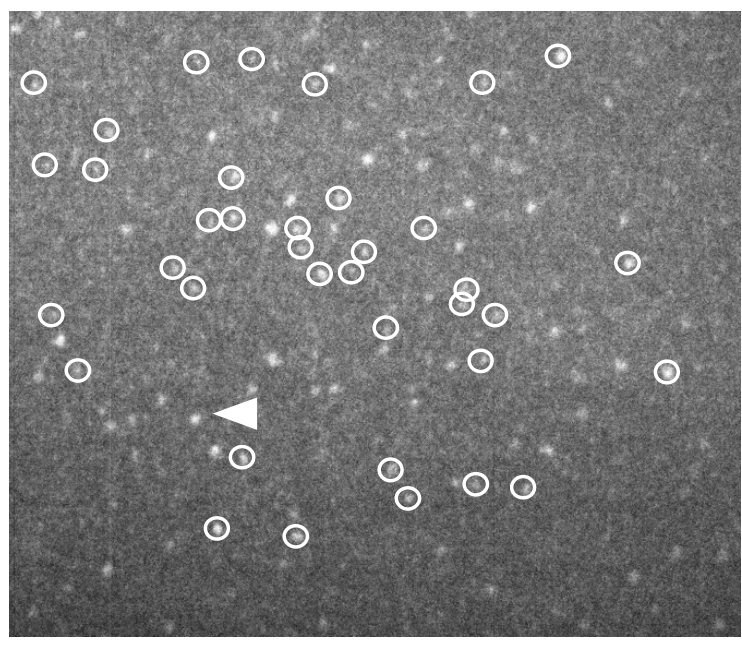

$6.3 \times 10^{18}$ ions $/ \mathrm{m}^{2}$ ( 1 dpa)

Fig. 7. The DF images of the same specimen area in an aged CF8 specimen before and after irradiation of 1 $\mathrm{MeV} \mathrm{Kr}$ at $300^{\circ} \mathrm{C}$ to a dose of $6.25 \times 10^{18}$ ions $/ \mathrm{m}^{2}$ ( $\sim 1 \mathrm{dpa}$ ), using the diffraction spots of G-phase precipitates to image. The points with white contrast were the G-phase precipitates. The white arrow indicates the same precipitates before and after the irradiation. The dashed circles indicate precipitates that dissolved after irradiation. The complete circles indicate precipitates that were newly formed after irradiation. The precipitates not being circled were precipitates that survived through the irradiation. 


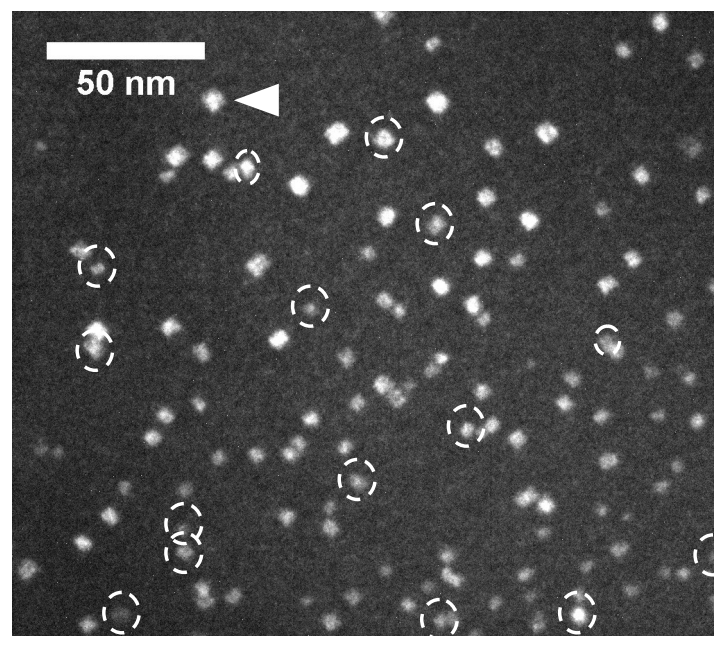

Before Irradiation

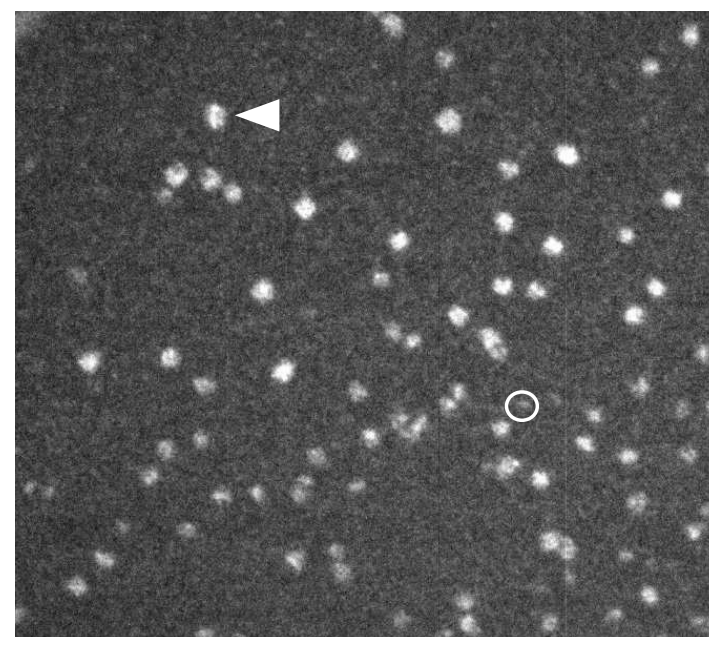

$6.3 \times 10^{18}$ ions $/ \mathrm{m}^{2}(\sim 1 \mathrm{dpa})$

Fig. 8 The DF images of the same specimen area of ferrite in the vicinity of ferrite-austenite phase boundary in an aged CF- 8 specimen before and after an irradiation of $1 \mathrm{MeV} \mathrm{Kr}$ at $300^{\circ} \mathrm{C}$ to a dose of $6.25 \times 10^{18}$ ions $/ \mathrm{m}^{2}(\sim 1 \mathrm{dpa})$, using the diffraction spots of G-phase precipitates to image. The descriptions for the circles and arrow are the same as in Fig. 7. 
(a) Distant from phase boundary

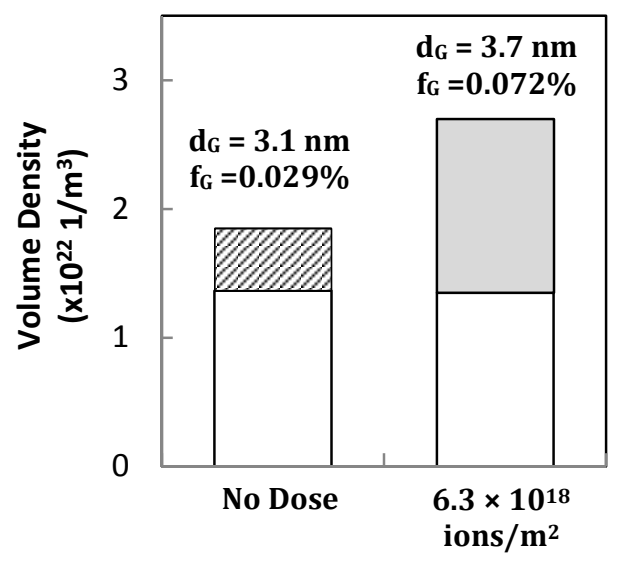

(b) Close to phase boundary decorated with $\mathrm{M}_{23} \mathrm{C}_{6}$ Carbides

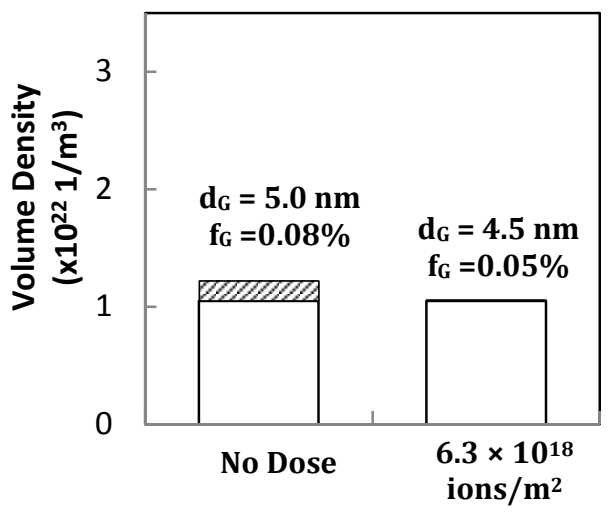

Fig. 9. The volume density change of G-phase precipitates due to $1 \mathrm{MeV} \mathrm{Kr}$ ions irradiations at $300^{\circ} \mathrm{C}$ to a fluence of $6.3 \times 10^{18}$ ions $/ \mathrm{m}^{2}$ ( 1 dpa) for (a) ferrite matrix and (b) regions of ferrite in the vicinity of $\mathrm{M}_{23} \mathrm{C}_{6}$ carbides. The white boxes represent the precipitates that remained intact through the irradiations. The boxes in shaded pattern represent the precipitates dissolved due to the irradiations. The grey boxes represent the precipitates produced by irradiations. $\mathrm{d}_{\mathrm{G}}$ is the average precipitate diameter. The $\mathrm{f}_{\mathrm{G}}$ is the volume fraction of the G-phase precipitates.

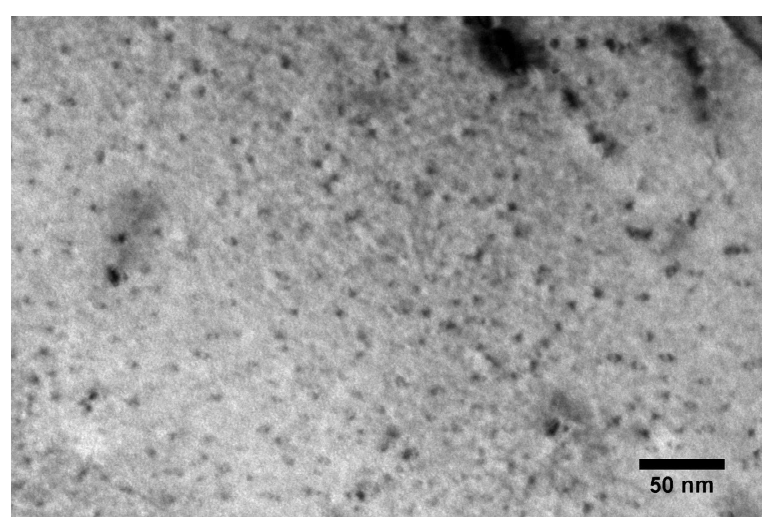

Before Irradiation

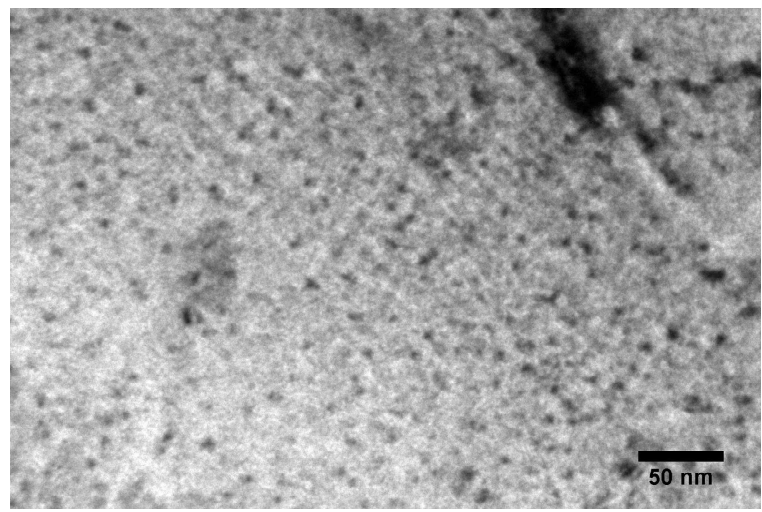

$6.3 \times 10^{18}$ ions $/ \mathrm{m}^{2}(\sim 1 \mathrm{dpa})$

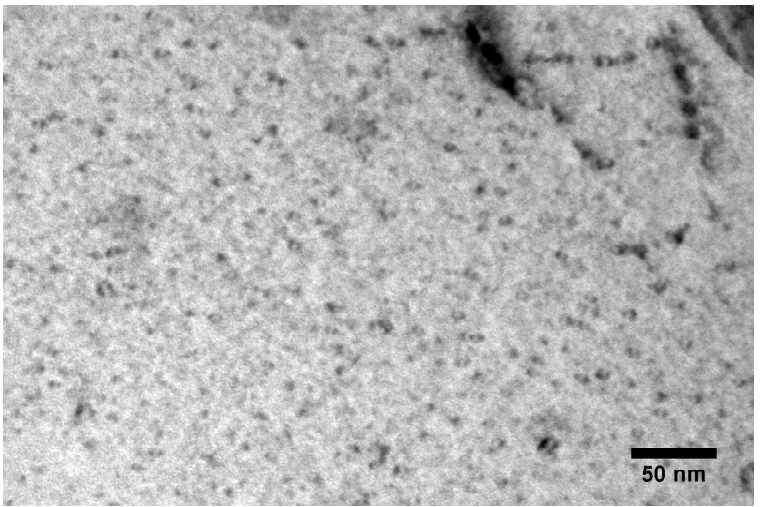

$3.1 \times 10^{18}$ ions $/ \mathrm{m}^{2}(\sim 0.5 \mathrm{dpa})$

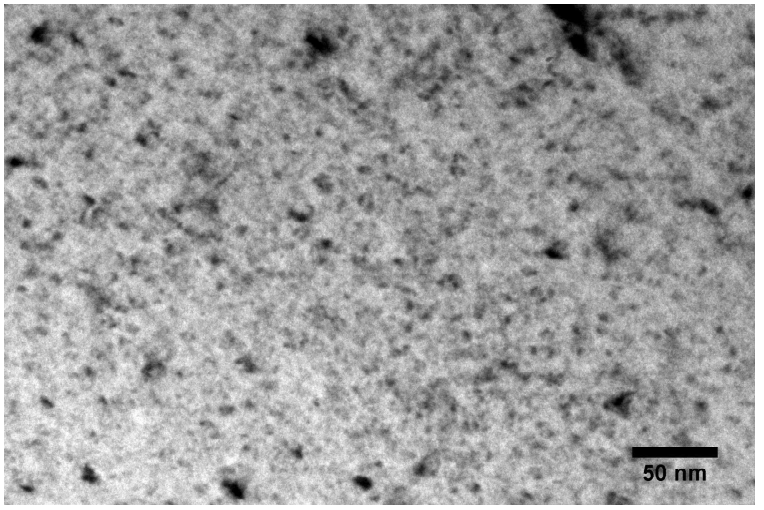

$1.3 \times 10^{19}$ ions $/ \mathrm{m}^{2}(\sim 2 \mathrm{dpa})$

Fig. 10. BF images showing G-phase precipitates in ferrite close to $\mathrm{M}_{23} \mathrm{C}_{6}$ carbides at ferrite-austenite phase boundary in an aged CF8 specimen irradiated at $300^{\circ} \mathrm{C}$. 


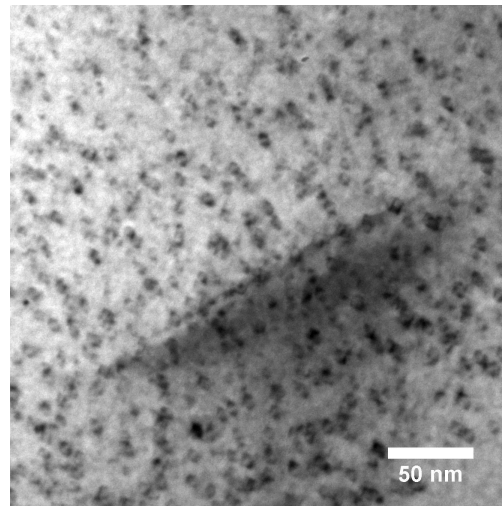

Before irradiation

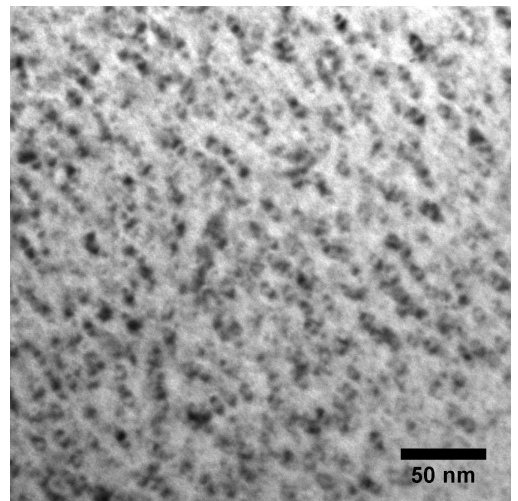

$6.3 \times 10^{18}$ ions $/ \mathrm{m}^{2}(\sim 1 \mathrm{dpa})$

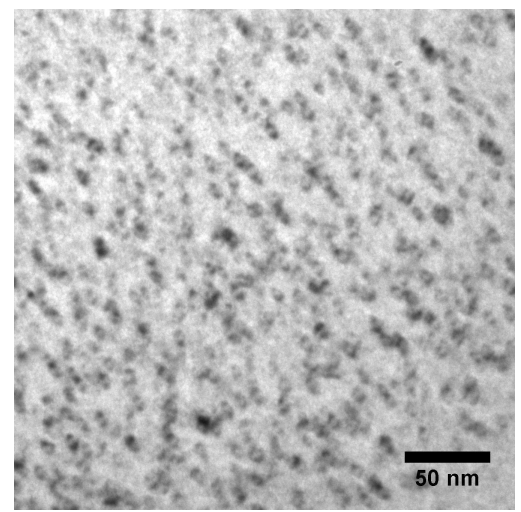

$1.5 \times 10^{18} \mathrm{ions} / \mathrm{m}^{2}(\sim 0.25 \mathrm{dpa})$

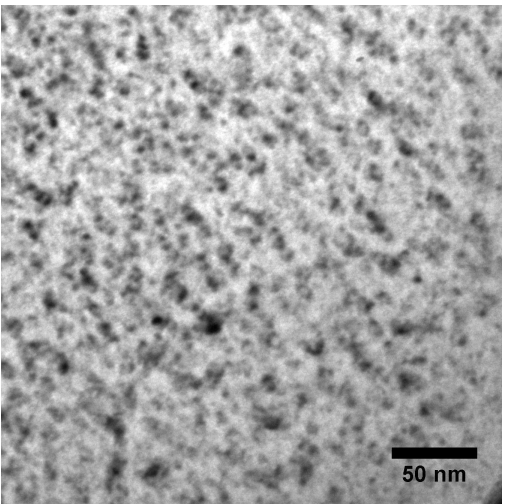

$1.3 \times 10^{19}$ ions $/ \mathrm{m}^{2}(\sim 2 \mathrm{dpa})$

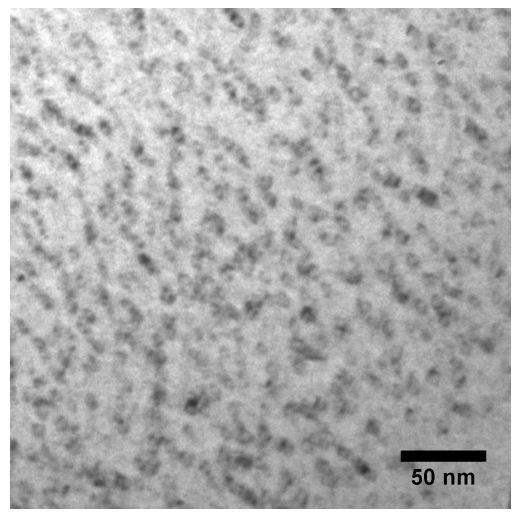

$3.1 \times 10^{18}$ ions $/ \mathrm{m}^{2}(\sim 0.5 \mathrm{dpa})$

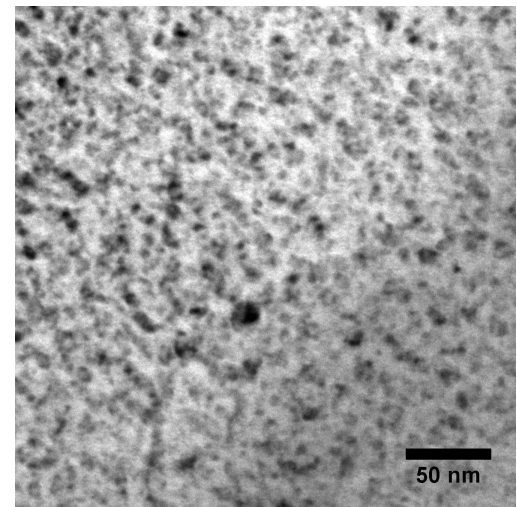

$1.9 \times 10^{19}$ ions $/ \mathrm{m}^{2}(\sim 3 \mathrm{dpa})$

Fig. 11. BF images showing G-phase precipitates in ferrite close to $\mathrm{M}_{23} \mathrm{C}_{6}$ carbides at ferrite-austenite phase boundary in an aged CF8 specimen irradiated at $400^{\circ} \mathrm{C}$. 


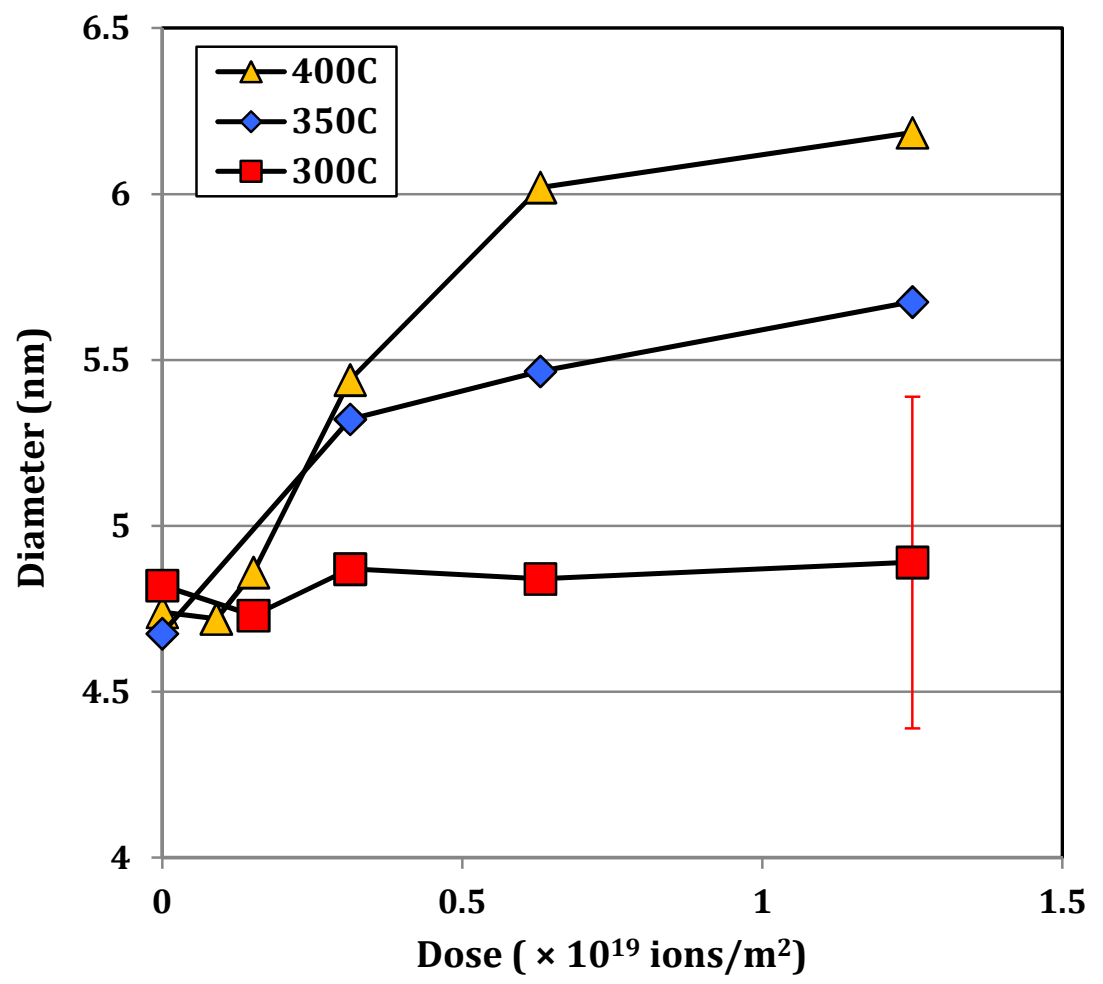

Fig. 12. The mean size of G-phase precipitates in the vicinity of $\mathrm{M}_{23} \mathrm{C}_{6}$ carbides at the ferrite-austenite phase boundary as a function of irradiation doses in aged CF8 irradiated at 300, 350 and $400{ }^{\circ} \mathrm{C}$. A representative uncertainty for the size measurement was shown in the figure. 
Table 1. Nominal Chemical Compositions (wt\%) of CF8 Grade Cast Stainless Steel [18]

\begin{tabular}{|c|c|c|c|c|c|c|c|c|c|}
\hline $\mathrm{C}$ & $\mathrm{Si}$ & $\mathrm{Mn}$ & $\mathrm{P}$ & $\mathrm{S}$ & $\mathrm{Ni}$ & $\mathrm{Cr}$ & $\mathrm{Mo}$ & $\mathrm{N}$ & $\mathrm{Fe}$ \\
\hline 0.063 & 1.07 & 0.64 & 0.021 & 0.014 & 8.08 & 20.46 & 0.31 & 0.062 & Bal. \\
\hline
\end{tabular}

